\title{
Drug resistance in rat colon cancer cell lines is associated with minor changes in susceptibility to cytotoxic cells
}

\author{
Wim Van de Vrie ${ }^{1,2}$, Sylke A. M. Van der Heyden³, Eric E. O. Gheuens ${ }^{3}$, Amelie M. Bijma², Ernst A. De Bruijn ${ }^{3}$, \\ Richard L. Marquet ${ }^{2}$, Allan T. Van Oosterom ${ }^{3}$, Alexander M. M. Eggermont ${ }^{1}$ \\ ${ }^{1}$ Department of Surgical Oncology, Rotterdam Cancer Center, Groene Hilledijk 301, 3075 EA Rotterdam, The Netherlands \\ ${ }^{2}$ Laboratory for Experimental Surgery, Erasmus University, PO Box 1738, 3000 DR Rotterdam, The Netherlands \\ ${ }^{3}$ Laboratory of Cancer Research and Clinical Oncology, Antwerp University, B-2610 Wilrijk, Belgium
}

Received: 22 February 1993 / Accepted: 12 July 1993

\begin{abstract}
The development of resistance to anticancer drugs urges the search for different treatment modalities. Several investigators have reported the concomitant development of drug resistance and resistance to natural killer (NK), lymphokine-activated killer (LAK) or monocyte/macrophage cell lysis, while others described unchanged or even increased susceptibility. We investigated this subject in the rat colon carcinoma cell line, CC531PAR, which is intrinsically multidrug-resistant (MDR), and in three sublines derived from this parental cell line: a cell line with an increased MDR phenotype (CC531-COL), a revertant line from CC531-COL (CC531-REV), which demonstrates enhanced sensitivity to anticancer drugs of the MDR phenotype, and an independently developed cisplatin-resistant line (CC531-CIS). In a 4-h ${ }^{51} \mathrm{Cr}$-release assay we found no difference in susceptibility to NK cell lysis. No significant differences in lysability by adherent LAK (aLAK) cells were observed in a 4-h assay. In a prolonged $20-\mathrm{h}{ }^{51} \mathrm{Cr}$-release assay an enhanced sensitivity to aLAK-cell-mediated lysis was observed in the revertant, P-glycoprotein-negative cell line and in the cisplatin-resistant cell line (CC531-CIS). None of the cell lines was completely resistant to lysis by aLAK cells. Therefore, a role for immunotherapy in the treatment of drug-resistant tumors remains a realistic option.
\end{abstract}

Key words: Interleukin-2 - Adherent lymphokine-activated killer - Natural killer - Multidrug resistance - Cisplatin resistance
Correspondence to: W. Van de Vrie, Department of Surgical Oncology, Rotterdam Cancer Center, Groene Hilledijk 301, 3075 EA Rotterdam, The Netherlands

\section{Introduction}

One of the major problems in cancer chemotherapy is the development of resistance to drugs. Several mechanisms of drug resistance have been elucidated; some operate against a particular drug, while others affect a group of structurally unrelated anticancer agents, as in multidrug resistance (MDR). Doxorubicin, vincristine and etoposide are examples of drugs subjected to the MDR mechanism. Multidrug-resistant cells express an efflux pump, $\mathrm{P}$ glycoprotein (Pgp), which expels anticancer drugs from the cells. Expression of the multidrug transporter can be demonstrated by anti-Pgp monoclonal antibodies, or at the DNA and RNA level by blotting techniques [26]. Resistance to a specific drug may be caused by several mechanisms. For instance, resistance to cisplatin is related to reduced drug accumulation, increased detoxification and increased DNA repair [2]. The development of resistance to anti-cancer drugs urges the search for alternative treatment modalities, for example immunotherapy. Adoptive immunotherapy using interleukin-2 (IL-2) and cytotoxic cells [lymphokineactivated killer (LAK) cells] has proven to be effective in renal cell cancer. Response rates up to $35 \%$ have been reported. In melanoma, responses up to $21 \%$ were found. Response rates in colon carcinoma were lower (13\%) [32]. All these tumors intrinsically express the MDR phenotype at a high frequency [15] (W. Van de Vrie et al., in preparation).

Before immunotherapy can be used as an alternative treatment after failure of chemotherapy, it is important to know whether there might be a correlation between drug resistance and sensitivity or resistance to immunotherapy. Reports in the literature have yielded conflicting data about a possible correlation between drug resistance, especially MDR, and resistance to natural killer (NK) and LAK cell lysis $[33,34]$. We investigated this subject in four cell lines of a rat colon carcinoma with different mechanisms and levels of drug resistance. In our model drug resistance was not associated with changes in sensitivity to NK-cell-mediated lysis. Only minor alterations in sensitivity to IL-2/adherent LAK (aLAK) cell lysis were observed. 


\section{Materials and methods}

Animals. Male rats of the inbred WAG/RIJ (RT1 ${ }^{\mathrm{u}}$ ) strain were obtained from Harlan-CPB (Austerlitz, The Netherlands). Animals were bred under specific-pathogen-free conditions and fed standard rat chow (Hope Farms, Woerden, The Netherlands) and water ad libitum. In the experiments, rats of 12-18 weeks old, weighing $220-280 \mathrm{~g}$, were used.

Cell lines. CC531 is a rat colon adenocarcinoma, which was induced chemically in the WAG rat with 1,2-dimethylhydrazine. The moderately differentiated tumor is weakly immunogenic, as determined by the method described by Prehn and Main [27], and transplantable in syngeneic rats [20]. Following subcutaneous implantation and subsequent resection, the tumor metastasizes to the lungs. In vivo the tumor is resistant to most anticancer drugs and only at the maximal tolerable dose were significant growth-retarding effects observed [19] (unpublished observations). Cisplatin was reported to be one of the most effective drugs against CC531 [19]. Moderate sensitivity to immunotherapeutic agents like interferon $\gamma$ and tumor necrosis factor $\alpha$ in vitro and in vivo has been shown in previous studies $[8,20,21,36]$. In vitro CC531, the parental cell line (CC531-PAR), grows as a monolayer in Dulbecco's modified Eagle's medium (DMEM) supplemented with 5\% heat-inactivated fetal calf serum (FCS), L-aspargine $(50 \mathrm{mg} / \mathrm{l})$, glutamic acid $(2 \mathrm{mM}), 100$ $\mathrm{IU} / \mathrm{ml}$ penicillin and $100 \mu \mathrm{g} / \mathrm{ml}$ streptomycin, all obtained from Gibco (Paisley, UK), in a humidified atmosphere of $5 \% \mathrm{CO}_{2} / 95 \%$ air at $37^{\circ} \mathrm{C}$. CC531-PAR intrinsically expresses the MDR phenotype. We recently reported on the reversibility of MDR in vitro and in vivo in this model [38]. In vitro drug resistant sublines were induced by continuous incubation with colchicin (CC531-COL) and cisplatin (CC531-CIS). Established cell lines were maintained in the presence of $0.2 \mu \mathrm{M}$ colchicin and $0.75 \mu \mathrm{M}$ cisplatin (cis-diaminedichloroplatinum) respectively [14]. Compared to the parental line, CC531-COL shows enhanced resistance to drugs of the MDR phenotype (colchicin $33 \times$, daunorubicin $10 \times$ ) and to cisplatin $(5.5 \times)$. CC531-CIS is resistant to cisplatin $(9.8 \times)$, while it has approximately the same sensitivity to other drugs as the parental line. From CC531-COL a revertant line (CC531-REV) was isolated that is more sensitive to drugs of the MDR phenotype than the parental line

Table 1. Characteristics of the CC531 cell lines

\begin{tabular}{|c|c|c|c|c|}
\hline Characteristic & CC531-PAR & CC531-COL & CC531-REV & CC531-CIS \\
\hline $\mathrm{RF}^{\mathrm{a}} \mathrm{DNR}^{\mathrm{b}}$ & 1 & 10 & 0.25 & 0.2 \\
\hline RF COL & 1 & 33 & 0.6 & 0.94 \\
\hline RF VBL & 1 & 4.4 & 0.3 & 1.0 \\
\hline RF CIS & 1 & 5.5 & 4 & 9.8 \\
\hline $\mathrm{SR}^{\mathrm{c}} \mathrm{VPL}$ & 6.6 & 31.6 & 2.0 & 5.0 \\
\hline $\begin{array}{l}\text { DNR } \\
\text { accumulation }^{\mathrm{d}}\end{array}$ & 100 & 64 & 102 & $\mathrm{ND}^{\mathrm{e}}$ \\
\hline $\begin{array}{l}\text { Pgp } \\
\text { expresssion }^{\mathrm{f}}\end{array}$ & + & ++ & \pm & ND \\
\hline
\end{tabular}

a RF, resistance factor. Drug sensitivity was determined with the 3-(4,5dimethylthiazol-2-yl)-2,5-diphenyltetrazolium bromide (MTT) colorimetric cell-growth-inhibition assay for different drugs. In the table the relative sensitivity of the cell lines compared to the parental line is given. The sensitivity of CC531-PAR is arbitrarily defined as 1

b DNR, daunorubicin; COL, colchicin; VBL, vinblastine; CIS, cis-diaminedichloroplatinum; VPL, verapamil

c SR, sensitization ratio. The DNR concentration that causes $50 \%$ growth inhibition ( $\mathrm{IC}_{50}$ ) in the MTT assay divided by the DNR concentration in the presence of $6.6 \mu \mathrm{M}$ verapamil that reaches the $\mathrm{IC}_{50}$

d The percentage intracellular fluorescent DNR determined in an accumulation assay by flow cytometry. The fluorescence of DNR in the parental line is defined as $100 \%$

e ND, not done

$\mathrm{f} P$ glycoprotein expression in cells was determined by flow cytometry with the monoclonal antibody $\mathrm{C}-219$. The immunofluorescence staining is indicated with +++ for bright staining, ++ for clear,+ for moderate, \pm for feeble, and - for no staining (resistance to colchicin $0.6 \times$, to daunorubicin $0.25 \times$ ), but the resistance to cisplatin is maintained $(4 \times)$ as in the CC531-COL line $[13,14]$. See Table 1 for characteristics.

YAC-1, a mouse T cell lymphoma, sensitive to NK cell lysis, was used as a positive control in the NK cell experiments. P815, a mouse mastocytoma, NK-cell-lysis-resistant but sensitive to LAK cell lysis, was used as a negative control in NK cell experiments and as a positive control in aLAK cell cytotoxicity tests. Both cell lines were grown in suspension in RPMI-1640 medium, (Dutch modification; Gibco) supplemented with $10 \%$ FCS, $2 \mathrm{mM}$ glutamine, $100 \mathrm{IU} / \mathrm{ml}$ penicillin and 100 $\mu \mathrm{g} / \mathrm{ml}$ streptomycin.

Cell lines were grown in drug-free medium for at least $72 \mathrm{~h}$ before being used in tests. Adherent growing cells were isolated by trypsinization. Viability, determined by trypan blue exclusion, was more than $90 \%$ in all experiments (85\% for YAC-1 and P815 cells). Regular screening for Mycoplasma infection was performed.

The NK and aLAK cell experiments were conducted in complete RPMI medium (10\% FCS) without HEPES buffer. Complete LAK medium for the generation of aLAK cells consisted of complete RPMI medium plus 1000 EuroCetus units $\Pi \mathrm{L}-2 / \mathrm{ml}$ and $50 \mu \mathrm{M}$ 2-mercaptoethanol.

Chemicals. 2-Mercaptoethanol was obtained from J.T. Baker, Deventer, The Netherlands; interleukin-2 (IL-2) from EuroCetus, Amsterdam, The Netherlands; $1 \%$ sodium dodecyl sulfate from Merck, Darmstadt, Germany; sodium $\left[{ }^{51} \mathrm{Cr}\right]$ chromate from Amersham, Aylesbury, UK.

Preparation of effector cells. Spleens were removed aseptically from the rats and crushed with the hub of a syringe in complete medium. Spleen cells were incubated for $5 \mathrm{~min}$ at $37^{\circ} \mathrm{C}$ in a buffered ammonium chloride solution to lyse the erythrocytes. For the NK cytotoxicity tests cells were rested for $1 \mathrm{~h}$ in complete medium at $37^{\circ} \mathrm{C}$ in $25-\mathrm{cm}^{2}$ culture flasks (Costar, Cambridge, Mass.) to remove the macrophages by adherence to the plastic. The remaining free-floating cells were aspirated, counted, and added to 96-well round-bottomed microtiter plates (Costar). In the NK cell lysis tests effector:target (E:T) cell ratios were 200:1, 100:1, 50:1 and 25:1.

For the aLAK cell cytotoxicity tests cells were passed over nylonwool columns to remove monocytes/macrophages and B cells [17]. Samples containing $2 \times 10^{8}$ spleen cells were added to a syringe containing $0.6 \mathrm{~g}$ sterile nylon wool (Cellular Products, Buffalo, N.Y.) and incubated for $1 \mathrm{~h}$ at $37^{\circ} \mathrm{C}$. The nonadherent cells were carefully washed out with $50 \mathrm{ml}$ medium. These cells were cultured at a concentration of $2 \times 10^{6}$ cells in $75-\mathrm{cm}^{2}$ culture flasks in LAK medium for $24 \mathrm{~h}$. Then only the cells adherent to the plastic of the flasks were cultured further in conditioned medium to make the aLAK cell bulk culture. Conditioned medium was prepared by decanting the medium from the flasks, removing the nonadherent cells by centrifugation and passing the supernatant through a $0.45-\mu \mathrm{m}$ Millipore filter [40]. After $72 \mathrm{~h}$ all cultured cells were collected; the adherent cells by adding EDTA and scraping the flask with a rubber policeman. In the aLAK cell lysis experiments E:T cell ratios were $50: 1,25: 1,12.5: 1$ and $6.25: 1$.

Cytotoxicity assay. Sensitivity to NK and aLAK cells was tested in the ${ }^{51} \mathrm{Cr}$-release cytotoxicity assay. Samples containing $1 \times 10^{6}$ target cells were incubated for $1 \mathrm{~h}$ with $200 \mu \mathrm{Ci}{ }^{51} \mathrm{Cr}$ in $200 \mu \mathrm{l}$ medium. Cells were washed three times with complete medium and counted, and $1 \times 10^{4}$ cells in $100 \mu \mathrm{l}$ complete medium were added to the effector cells $(100 \mu \mathrm{l})$ in the plates. Spontaneous release was tested in wells containing target cells and medium $(100 \mu \mathrm{l})$ only; maximal release was obtained by adding 100 $\mu 11 \%$ sodium dodecyl sulfate to target cells. Tests were performed in triplicate and all tests were repeated at least twice. Plates were incubated for $4 \mathrm{~h}$ at $37^{\circ} \mathrm{C}$. The supernatant was harvested using the Skatron supernatant collection system (Skatron, Lier, Norway). The release of ${ }^{51} \mathrm{Cr}$ was determined by counting radioactivity in a gamma counter (LBK Wallace Ultragamma II 1280, Wallace Instruments, Stockholm, Sweden). The percentage specific cytotoxicity was calculated by the following formula: 


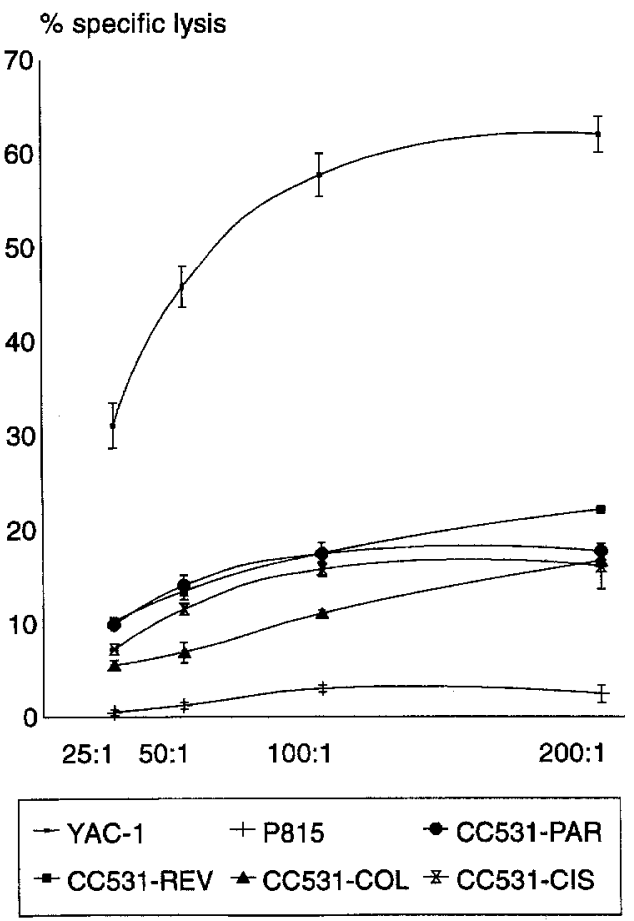

Fig. 1. Natural killer (NK) cell lysis determined in a 4-h ${ }^{51} \mathrm{Cr}$-release assay. Mean specific lysis by NK cells of YAC-1 (positive control), P815 (negative control) and the cell lines CC531-PAR, CC531-REV, CC531COL and CC531-CIS at E:T ratios of 25:1, 50:1, 100:1 and 200:1 is presented in the graph. Error bars are standard errors of the mean

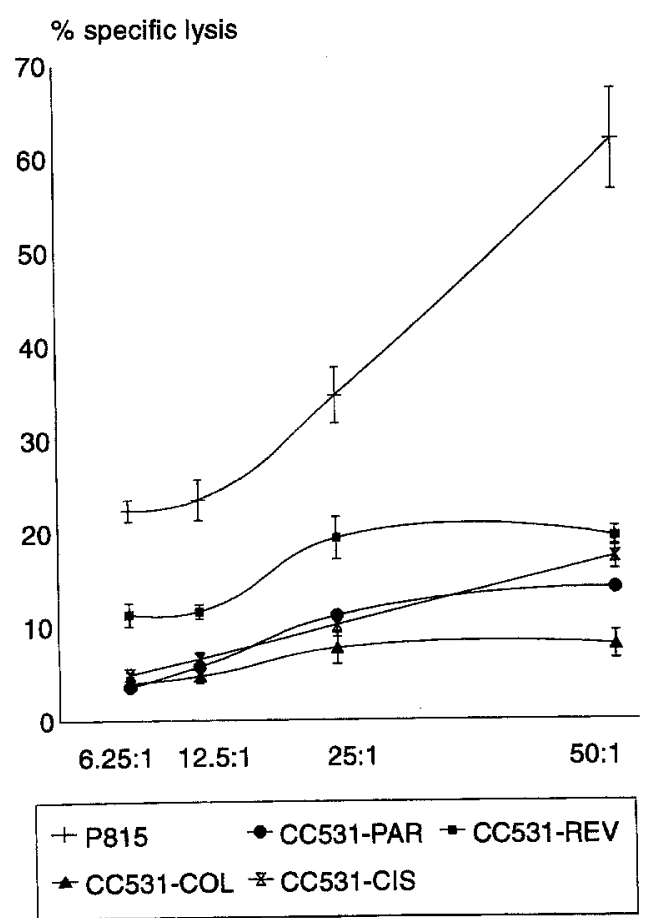

Fig. 2. Adherent lymphokine-activated killer (aLAK) cell lysis determined after $4 \mathrm{~h}$. Mean specific lysis ( \pm SE) by aLAK cells of P815 (positive control) and the cell lines CC531-PAR, CC531-REV, CC531COL and CC531-CIS at E:T ratios of 6.25:1, 12.5:1, 25:1 and 50:1 is presented in the graph. Statistical significance at the 50:1 E:T ratio determined on the compilation of tests was found between CC531-CIS and CC531-COL $(P=0.019)$

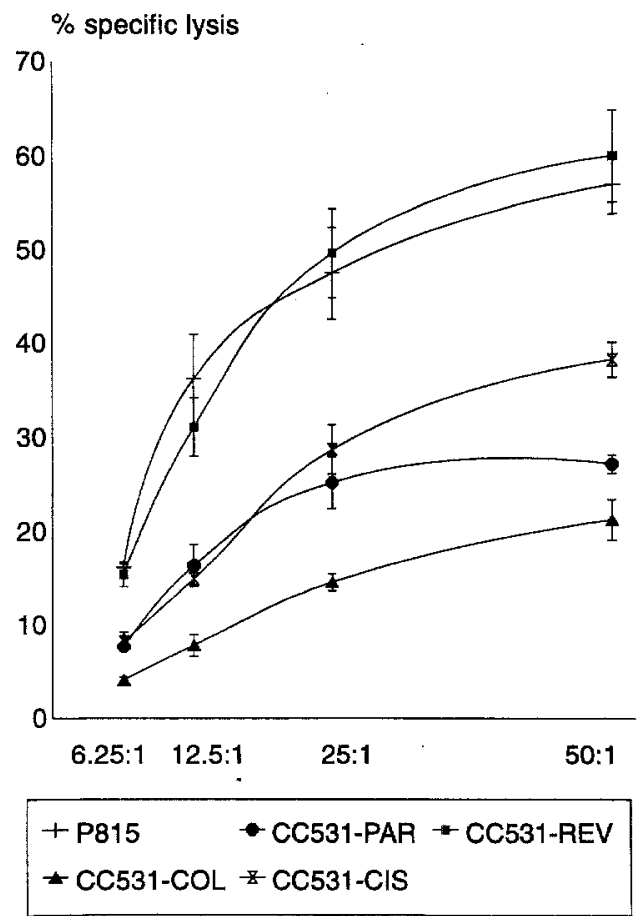

Fig. 3. Adherent lymphokine-activated killer (aLAK) cell lysis determined after $20 \mathrm{~h}$. Mean specific lysis ( \pm SE) by aLAK cells of P815 (positive control) and the cell lines CC531-PAR, CC531-REV, CC531COL and CC531-CIS at E:T ratios of 6.25:1, 12.5:1, 25:1 and 50:1 is presented in the graph. Statistically significant differences at the 50:1 E:T ratio determined on the compilation of tests: CC531-CIS versus CC531COL, $P=0.023$; CC531-REV versus CC531-COL, $P=0.002$; CC531REV versus CC531-PAR, $P=0.02$

specific cytotoxicity $(\%)=$

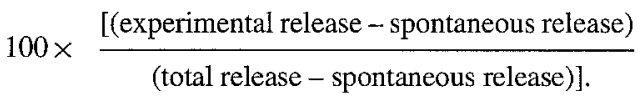

Lytic units (LU) were calculated according to the method described by Pross et al. [28]. The calculations of lytic units and of statistical significance were done on the compilations of different tests. In figures, representative experiments are shown.

Statistics. Statistical significance of the results was determined at the highest E:T ratios: 200:1 for NK cell lysis and 50:1 for aLAK cell lysis. The Student $t$-test (paired $t$-test) was used and a $P$ value of less than 0.05 was considered significant.

\section{Results}

NK cells of the WAG rat were highly effective against the NK-sensitive YAC-1 cell line; up to $60 \%$ lysis was observed. The NK-resistant cell line P815 was not lysed at all: less than 5\% lysis was recorded at the 100:1 and 200:1 E:T cell ratios. The CC531 cell lines were rather resistant to NK cell lysis. At the highest (200:1) E:T cell ratio $15 \%-22 \%$ specific lysis was found. See Fig. 1 . There were no significant differences in sensitivity between the CC531 cell lines.

We used aLAK cells instead of LAK cells because the adherent cells were proven to be the most effective cytotoxic cells in bulk cultures with IL-2 [40]. A representative 
Table 2. Activity of natural killer (NK) and adherent lymphokine-activated killer (aLAK) cells

\begin{tabular}{llll}
\hline Cell line & \multicolumn{3}{l}{ Activity $\left(\mathrm{LU} / 10^{6} \text { cells }\right)^{\mathrm{a}}$} \\
\cline { 2 - 3 } & $\mathrm{NK}$ & aLAK 4h & aLAK 20 h \\
\hline YAC-1 & 5.5 & & \\
P815 & 0 & 10.4 & 21.7 \\
CC531-PAR & 0 & 0 & 10.1 \\
CC531-REV & 0.6 & 3.2 & 13.9 \\
CC531-COL & 0.3 & 0 & 7.1 \\
CC531-CIS & 1.5 & 6.0 & 14.4 \\
\hline
\end{tabular}

a Lytic units $/ 10^{6}$ effector cells based on $15 \%$ lysis

experiment for lysis by aLAK cells in a standard 4- $\mathrm{h} 51 \mathrm{Cr}$ release assay is shown in Fig. 2. Maximal lysis of P815 was more than $60 \%$, while lysis of the CC531 cell lines did not exceed $20 \%$. At the maximal E:T ratio of $50: 1$ only minor differences in lysis were observed between some cell lines. CC531-CIS was significantly more sensitive to aLAK lysis compared to the least lysable cell line CC531-COL.

As there were indications that the resistance to lysis by cytotoxic cells could be overcome by prolonging the incubation period, we extended the aLAK tests to $20 \mathrm{~h}$. In these prolonged tests P815 cells appeared to be fragile as the spontaneous release was more than $25 \%$. Specific lysis of P815 by aLAK cells was not enhanced by longer exposure to the cytotoxic cells in comparison with $4 \mathrm{~h}$ exposure. In all CC531 cell lines spontaneous release after $20 \mathrm{~h}$ was about 20\%; CC531-PAR: $19.7 \pm 2.6 \%$ (SD), CC531COL: $19.8 \pm 3.7 \%$, CC531-REV: $20.1 \pm 7.3 \%$, and CC531-CIS: $20.6 \pm 6.0 \%$. In this prolonged assay none of the CC531 cell lines proved resistant to lysis by aLAK cells; specific lysis was more than $25 \%$ in all cell lines. Differences in sensitivity between the sublines became clearer (Fig. 3). In the compilation of tests CC531-COL appeared the most resistant line and, at the 50:1 E:T ratio, less than 30\% lysis was found. CC531-REV and CC531CIS proved to be the most lysable with more than $50 \%$ lysis after $20 \mathrm{~h}$. The differences between CC531-REV and CC531-COL, and CC531-CIS and CC531-COL were significant. The same significant difference was found for CC531-REV compared to CC531-PAR, while CC531-CIS was found significantly more sensitive to aLAK lysis than the parental line in three out of four tests, but not in the compilation of four tests. Lytic units as values of cytotoxicity show the same order of sensitivity to aLAK cell mediated lysis in the 20-h assay, but differences between the cell lines are small. See Table 2.

\section{Discussion}

CC531 cells appeared to be rather resistant to lysis by cytotoxic cells. NK cell lysis was below $22 \%$ in all cell lines even at an E:T ratio of 200:1. No differences in specific lysis were observed between the CC531 cell lines. Lysis by IL-2-induced cytotoxic cells, aLAK cells, still was very low at a 50:1 E:T ratio, but some difference between the cell lines became apparent. We studied these differences in a prolonged assay. None of the cell lines was found to be completely resistant to aLAK lysis. The most drug-sensitive cell line, CC531-REV, with the least expression of Pgp was the most sensitive to aLAK lysis, while the most drug resistant cell line, CC531-COL, seemed the most resistant to aLAK lysis.

So far conflicting results have been reported about a possible correlation between drug resistance and sensitivity to NK cell lysis. Various reports about doxorubicin-induced drug resistance showed enhanced resistance to NKcell-mediated lysis in doxorubicin-resistant sublines [3, 6 , $41,43]$. In MDR cell lines, both no change in sensitivity [1, $5,16,35]$ and also enhanced sensitivity to NK cell lysis compared to the parental cell lines [34] has been described. In contrast, Woods et al. reported diminished NK sensitivity of an MDR subline with enhancement of sensitivity in a revertant cell line [42]. Treichel et al. only found this relationship for MDR cell lines that express Pgp, and not for non-Pgp MDR cell lines [37].

With regard to LAK cell sensitivity, various studies show no difference in lysability between drug-resistant cell lines and their parental lines [1, 3, 4, 12, 16, 25, 35]. Enhanced sensitivity as well as enhanced resistance of MDR cell lines to LAK cell lysis has been reported by others $[10,11,12,18,30,37]$. An inverse relationship has also been found: the induction of LAK resistance in melanoma cell lines rendered these more sensitive to doxorubicin [29]. Kimmig et al. found that LAK resistance correlated with the level of Pgp expression. A revertant cell line that was as drug sensitive as the parental line was found to be as lysable by LAK cells as the parental cell line [18]. We did a comparable observation with the CC531 cell lines in the prolonged aLAK lysis assay.

Explanations for the phenomenon of differences in sensitivity to cytotoxic cells between drug-sensitive and drugresistant cells have been sought in differences in the expression of cell membrane molecules. In most studies no correlation between MDR expression, NK or LAK cell resistance and expression of MHC class I and II antigens was observed $[10,31,35]$. With regard to adhesion molecules a correlation between enhanced LAK cell lysis and ICAM-1 and LFA-3 expression in MDR cell lines was described [31], but other authors could not confirm these results using other cell lines [35].

To our knowledge only few reports about the association between cisplatin resistance and NK/LAK cell resistance have been published. In most experiments no influence of cisplatin resistance on sensitivity to LAK-cell-mediated lysis was observed $[4,16,25,29]$. In one of their cisplatin-resistant cell lines Ohtsu et al. found enhanced sensitivity to LAK cell lysis [25]. Allevana et al. reported significant lysis by LAK cells of freshly isolated tumor cells from ovarian cancer patients that were refractory to chemotherapy with cisplatin [4]. In a recent article shortterm pretreatment of cancer cells with cisplatin was reported to render these cells more sensitive to cytotoxic cells [24]. We observed enhanced lysis by aLAK cells of the cisplatin-resistant cell line CC531-CIS. In CC531-COL and CC531-REV cells a moderate resistance to cisplatin was found, about half the resistance of CC531-CIS. In 
these two cell lines an association between their MDR phenotype and LAK resistance can be supposed, while the resistance to cisplatin seems of no importance. It is very possible that the colchicin induced MDR cell line CC531COL and its revertant CC531-REV have a different mechanism of cisplatin resistance from CC531-CIS, as this resistance was induced differently.

It is clear from our results and those of others that basic research has not yet provided coherent data on the relationship between drug resistance and sensitivity to immunotherapy. The lack of coherence in the results may be inherent to the different cell lines and the diversity of methods used to induce resistance. Possibly this reflects the heterogeneity of sensitivity and resistance to drugs and immunotherapy in the clinical situation. Our results seem to indicate that drug resistance does not preclude the use of immunotherapy with IL-2 and LAK cells, but enhancement of the efficacy of immunotherapy is necessary. With regard to Pgp-expressing multidrug-resistant tumors, an attractive approach might be to turn the strength of MDR cells into their weakness. This can be done by using antibodies against the multidrug transporter Pgp. Immunotoxin therapy using the anti-Pgp antibody MRK16 coupled to Pseudomonas exotoxin has been shown to be effective against MDR cells in vitro and in vivo $[9,22,23]$. Another possible method of targeted immunotherapy is the use of bispecific monoclonal antibodies directed against Pgp on one hand and against an antigen on cytotoxic cells on the other $[7,39]$. Further research in this direction is warranted.

Acknowledgements. We would like to thank H.J. Elst and N.M.C. Durante for their skilful technical assistance. This work was supported by the Dr. Daniel den Hoed Foundation, Rotterdam, The Netherlands.

\section{References}

1. Ades EW, Bosse D, Pruckler J (1990) Potentiation of human natural killer cell activity by recombinant interleukin-2 towards multidrugresistant human epidermoid carcinoma. Pathobiology 58: 84

2. Andrews PA, Howell SB (1990) Cellular pharmacology of cisplatin: perspectives on mechanisms of acquired resistance. Cancer Cells 2: 35

3. Allavena P, Grandi M, D'Incalci M, Geri O, Giuliani FC, Mantovani A (1987) Human tumor cell lines with pleiotropic drug resistance are efficiently killed by interleukin- 2 activated killer cells and by activated monocytes. Int J Cancer 40: 104

4. Allavena P, Damia G, Colombo T, Maggioni D, D'Incalci M, Mantovani A (1989) Lymphokine-activated killer (LAK) and monocytemediated cytotoxicity on tumor cell lines resistant to antitumor agents. Cell Immunol 120: 250

5. Allavena P, Peccatori F, Maggioni D, Pirovano P, Mantovani A (1989) Killing of tumor cells with pleiotropic drug resistance by OK432-activated effector cells. Immunopharmacol Immunotoxicol 11: 257

6. Benoist H, Madoulet C, Jardillier J-C, Desplaces A (1985) Adriamycin induced resistance of sensitive $\mathrm{K} 562$ cells to natural killer lymphocyte attack. Cancer Immunol Immunother 20: 122

7. Bolhuis RL, Sturm E, Braakman E (1991) T cell targeting in cancer therapy. Cancer Immunol Immunother 34: 1

8. Eggermont AMM, Marquet RL, De Bruin RWF, Jeekel J (1986) Effects of the interferon-inducer ABPP on colon cancer in rats: importance of tumor load and tumor site. Cancer Immunol Immunother 22: 217
9. FitzGerald DJ, Willingham MC, Cardarelli CO, Hamada H, Tsuruo T, Gottesman MM, Pastan I (1987) A monoclonal antibody-Pseudomonas toxin conjugate that specifically kills multidrug-resistant cells. Proc Natl Acad Sci USA 84: 4288

10. Gambacorti-Passerini C, Rivoltini L, Supino R, Mariani M, Parmiani $G$ (1988) Differential lysis of melanoma clones by autologous recombinant interleukin 2-activated lymphocytes. Relationship with spontaneous resistance to doxorubicin (Dx). Int J Cancer 42: 544

11. Gambacorti-Passerini C, Rivoltini L, Supino R, Rodolfo M, Radrizzani M, Fossati G, Parmiani G (1988) Susceptibility of chemoresistant murine and human tumor cells to lysis by interleukin 2 -activated lymphocytes. Cancer Res 48: 2372

12. Gautam SC, Chikkala NF, Lewis I, Grabowski DR, Finke JH, Ganapathi R (1992) Therapeutic efficacy of interleukin-2 activated killer cells against Adriamycin resistant mouse B 16-BL6 melanoma. Anticancer Res 12: 921

13. Gheuens EEO, Van Bockstaele DR, Van der Keur M, Tanke HJ, Van Oosterom AT, De Bruijn EA (1991) Flow cytometric double labelling technique for screening of multidrug resistance. Cytometry 12: 636

14. Gheuens EEO, Van der Heyden SAM, Elst HJ, Eggermont AMM, Van Oosterom AT, De Bruijn EA (1993) Multidrug resistance in rat colon carcinoma cell lines CC531, CC531 $\mathrm{mdr}+$ and CC531 ${ }^{\mathrm{rev}}$. Jpn J Cancer Res (in press)

15. Goldstein LJ, Galski H, Fojo A, Willingham M, Lai S-L, Gazdar A, Pirker R, Green A, Crist W, Brodeur GM, Lieber M, Cossman J, Gottesman MM, Pastan I (1989) Expression of a multidrug resistance gene in human cancers. J Natl Cancer Inst 81: 116

16. Harker WG, Tom C, McGregor JR, Slade L, Samlowski WE (1990) Human tumor cell line resistance to chemotherapeutic agents does not predict resistance to natural killer or lymphokine-activated killer cell-mediated cytolysis. Cancer Res 50:5931

17. Julius MH, Simpson E, Herzenberg LA (1973) A rapid method for the isolation of functional thymus derived murine lymnhocytes. Eur J Immunol 3: 645

18. Kimmig A, Gekeler V, Neumann M, Frese G, Handgretinger R, Kardos G, Diddens H, Niethammer D (1990) Susceptibility of multidrug-resistant human leukemia cell lines to human interleukin 2-activated killer cells. Cancer Res 50:6793

19. Los G, Nagel JD, McVie JG (1990) Anti-tumor effect of cisplatin, carboplatin, mitoxantrone, and doxorubicin on peritoneal tumor growth after intraperitoneal and intravenous chemotherapy: a comparative study. Sel Cancer Ther 6: 73

20. Marquet RL, Westbroek DL, Jeekel J (1984) Interferon treatment of a transplantable rat colon adenocarcinoma: importance of tumor site. Int J Cancer 33: 689

21. Marquet RL, IJzermans JNM, De Bruin RWF, Fiers W, Jeekel J (1987) Antitumor activity of recombinant mouse tumor necrosis factor (TNF) on colon cancer in rats is promoted by recombinant rat interferon gamma; toxicity is reduced by indomethacin. Int J Cancer 40: 550

22. Mickisch GH, Pai LH, Gottesman MM, Pastan I (1992) Monocional antibody MRK16 reverses the multidrug resistance of multidrug-resistant transgenic mice. Cancer Res 52: 4427

23. Mickisch GH, Pai LH, Siegmund M, Campain J, Gottesman MM, Pastan I (1993) Pseudomonas exotoxin conjugated to monoclonal antibody MRK16 specifically kills multidrug resistant cells in cultured renal carcinomas and in MDR-transgenic mice. J Urol 149: 174

24. Mizutani Y, Banovida B, Nio Y, Yoshida O (1993) Enhanced susceptibility of cis-diamminedichloroplatinum-treated K562 cells to lysis by peripheral blood lymphocytes and lymphokine activated killer cells. Cancer 71: 1313

25. Ohtsu A, Sasaki Y, Tamura T, Fujiwara Y, Ohe Y, Minato K, Nakagawa K, Bungo M, Saijo N (1989) Inhibition of colony formation of drug-resistant human tumor cell lines by combinations of interleukin-2-activated killer cells and antitumor drugs. Jpn J Cancer Res 80: 265

26. Pastan I, Gottesman M (1987) Multiple-drug resistance in human cancer. N Engl J Med 316: 1388

27. Prehn RT, Main JW (1957) Immunity to methylcholanthrene induced sarcomas. J Natl Cancer Inst 18: 769 
28. Pross HF, Baines MG, Rubin P, Shragge P, Patterson MS (1981) Spontaneous human lymphocyte-mediated cytotoxicity against tumor target cells. IX. The quantitation of natural killer cell activity. J Clin Immunol 1: 51

29. Rivoltini L, Gambacorti-Passerini C, Supino R, Parmiani G (1989) Generation and partial characterization of melanoma sublines resistant to lymphokine activated killer (LAK) cells. Relevance to doxorubicin resistance. Int J Cancer 43: 880

30. Rivoltini L, Colombo MP, Supino R, Ballinari D, Tsuruo T, Parmiani $G$ (1990) Modulation of multidrug resistance by verapamil or $m d r 1$ anti-sense oligodeoxynucleotide does not change the high susceptibility to lymphokine-activated killers in $m d r$-resistant human carcinoma (LoVo) line. Int J Cancer 46: 727

31. Rivoltini L, Cattoretti G, Arienti F, Mastroianni A, Melani C, Colombo MP, Parmiani G (1991) The high lysability by LAK cells of colon-carcinoma cells resistant to doxorubicin is associated with a high expression of ICAM-1, LFA-3, NCA and a less-differentiated phenotype. Int J Cancer 47: 746

32. Rosenberg SA (1991) Immunotherapy and gene therapy of cancer. Cancer Res 51: 5074s

33. Safrit JT, Bonavida B (1992) Hierarchy of in vitro sensitivity and resistance of tumor cells to cytotoxic effector cells, cytokines, drugs and toxins. (1992) Cancer Immunol Immunother 34: 321

34. Savas B, Cole SPC, Akoglu TF, Pross HF (1992) P-glycoprotein-mediated multidrug resistance and cytotoxic effector cells. Nat Immun 11: 177

35. Scheper RJ, Dalton WS, Grogan TM, Schlosser A, Bellamy WT, Taylor CW, Scuderi P, Spier C (1991) Altered expression of P-glycoprotein and cellular adhesion molecules on human multi-drug-resistant tumor cells does not affect their susceptibility to NK- and LAK-mediated cytotoxicity. Int J Cancer 48: 562
36. Scheringa M, IJzermans JNM, Jeekel J, Marquet RL (1990) The antitumour activity of the interferon inducer bropirimine is partially mediated by endogenous tumour necrosis factor- $\alpha$. Cancer Immunol Immunother 32: 251

37. Treichel RS, Olken S (1992) The relationship between multi-drug resistance and resistance to natural-killer-cell and lymphokine-activated killer-cell lysis in human leukemic cell lines. Int J Cancer 50: 305

38. Van de Vrie W, Gheuens EEO, Durante NMC, De Bruijn EA, Marquet RL, Van Oosterom AT, Eggermont AMM (1993) In vitro and in vivo chemosensitizing effect of cyclosporin- $\mathrm{A}$ on an intrinsic multidrug resistant rat colon tumour. J Cancer Res Clin Oncol 119: 609

39. Van Dijk J, Tsuruo T, Segal DM, Bolhuis RLH, Colognola R, Van de Griend RJ, Fleuren GJ, Warnaar SO (1989) Bispecific antibodies reactive with the multidrug-resistance-related glycoprotein and $\mathrm{CD} 3$ induce lysis of multidrug-resistant tumor cells. Int J Cancer 44: 738

40. Vujanovic NL, Herberman RB, Maghazachi AA, Hiserodt JC (1988) Lymphokine-activated killer cells in rats III. A simple method for the purification of large granular lymphocytes and their rapid expansion and conversion into lymphokine-activated killer cells. J Exp Med 167: 15

41. Wood WJ, Lotzovà E (1989) Adriamycin-induced resistance to natural killer (NK)-mediated cytotoxicity. Cancer 64: 396

42. Woods G, Lund LA, Naik M, Ling V, Ochi A (1988) Resistance of multidrug-resistant lines to natural killer-like cell-mediated cytotoxicity. FASEB J 2: 2791

43. Yanovich S, Hall RE, Weinert C (1986) Resistance to natural killer cell-mediated cytolysis by a pleiotropic drug-resistant human erythroleukemia (K562-R) cell line. Cancer Res 46: 4511 